\title{
Blue-LED-excitable NIR-II luminescent lanthanide-doped SrS nanoprobes for ratiometric thermal sensing
}

\author{
Jiaojiao Wei ${ }^{1,2}$, Youyu Liu ${ }^{1,2}$, Meiran Zhang ${ }^{2}$, Wei Zheng ${ }^{1,2,3^{*}}$, Ping Huang ${ }^{1,2,3}$, Zhongliang Gong ${ }^{2}$, \\ Renfu $\mathrm{Li}^{2,3}$ and Xueyuan Chen ${ }^{1,2,3^{*}}$
}

\begin{abstract}
Lanthanide ( $\left.\mathrm{Ln}^{3+}\right)$-doped near infrared (NIR)-II luminescent nanoprobes have shown great promise in many technological fields, but are currently limited by the low absorption efficiency of $\mathrm{Ln}^{3+}$ due to the forbidden $4 \mathrm{f} \rightarrow 4 \mathrm{f}$ transition. Herein, we report a novel NIR-II luminescent nanoprobe based on efficient energy transfer from $\mathrm{Ce}^{3+}$ to $\mathrm{Er}^{3+}$ and $\mathrm{Nd}^{3+}$ in sub-10 nm SrS nanocrystals (NCs), which are excitable by using a commercial blue light-emitting diode (LED). Through sensitization by the allowed $4 \mathrm{f} \rightarrow 5 \mathrm{~d}$ transition of $\mathrm{Ce}^{3+}$, the NCs exhibit strong NIR-II luminescence from $\mathrm{Er}^{3+}$ and $\mathrm{Nd}^{3+}$ with quantum yields of $2.9 \%$ and $2.3 \%$, respectively. Furthermore, by utilizing the intense NIR-II luminescence of $\mathrm{Er}^{3+}$ from the thermally coupled Stark sublevels of ${ }^{4} \mathbf{I}_{13 / 2}$, we demonstrate the application of SrS: $\mathrm{Ce}^{3+} / \mathrm{Er}^{3+} \mathrm{NCs}$ as blueLED-excitable NIR-II luminescent nanoprobes for ratiometric thermal sensing. These findings reveal the unique advantages of SrS: $\mathrm{Ln}^{3+}$ NCs in NIR-II luminescence, which may open up a new avenue for exploring novel and versatile luminescent nanoprobes based on $\mathrm{Ln}^{3+}$-doped sulphide NCs.
\end{abstract}

Keywords: SrS, lanthanide, near-infrared II, nanoprobe, thermal sensing

\section{INTRODUCTION}

Lanthanide $\left(\mathrm{Ln}^{3+}\right)$-doped luminescent nanocrystals (NCs) emitting in the second near-infrared (NIR-II: 1000-1700 nm) biological window have recently evoked considerable interest, owing to their superior optical properties such as high photochemical stability, sharp emission peaks, long photoluminescence (PL) lifetimes, and large antenna-generated Stokes shift, in parallel with the benefits of minimal background interference and deep tissue penetration of the NIR light [1-9]. These outstanding features make $\mathrm{Ln}^{3+}$-doped NIR-II luminescent NCs ideal candidates as an alternative to traditional fluorescent probes like organic dyes and quantum dots and as a new generation of luminescent nanoprobes in many technological fields, including deep-tissue bioimaging, non-invasive chemical/biological detection, high-seed optical communication, and non-contact thermal sensing [10-22]. Nonetheless, because of the parity-forbidden nature of the $4 \mathrm{f} \rightarrow 4 \mathrm{f}$ electronic transitions, $\mathrm{Ln}^{3+}$-doped NIR-II luminescent NCs normally suffer from low absorption and emission efficiencies, and exhibit low-tomedium brightness when compared with organic dyes and quantum dots [23-29]. Therefore, a high-power laser is generally demanded to realize bright NIR-II luminescence in $\mathrm{Ln}^{3+}$-doped NCs, which may limit their widespread applications.

To circumvent the limitation of $\mathrm{Ln}^{3+}$-doped NIR-II luminescent NCs, it is of fundamental importance to introduce an antenna that can effectively harvest the excitation light and sensitize the NIR-II luminescence of $\mathrm{Ln}^{3+}$ emitters [30-33]. In this regard, optical entities of allowed transitions with large absorption cross-sections such as $\mathrm{Ce}^{3+}, \mathrm{Bi}^{3+}$, ligand-to-metal charge transfer states, and the host absorption of semiconductors can be effective sensitizers for $\mathrm{Ln}^{3+}$ luminescence [34-37]. The absorption of these species, however, is influenced significantly by the host matrix with respect to the site symmetry, the crystal field (CF) strength, and the covalency [38-41]. Therefore, a judicious screening of host materials for both the sensitizers and $\mathrm{Ln}^{3+}$ emitters is essential to the design of efficient NIR-II luminescent nanoprobes with desired properties.

Hitherto, most of the reported $\mathrm{Ln}^{3+}$-doped NIR-II luminescent nanoprobes have been restricted to fluorides, probably due to the well-established synthetic methods for their upconversion analogues [42-45]. Until recently, the new class of NIR-II luminescent nanoprobes based on $\mathrm{Ln}^{3+}$-doped sulphides (namely, $\mathrm{CaS}$ and $\mathrm{NaGdS}_{2}$ ) have been proposed by our group $[46,47]$. In comparison with fluorides, sulphide NCs exert a stronger $\mathrm{CF}$ and a higher covalency on $\mathrm{Ln}^{3+}$ emitters [48-50]. As a result, the absorption and emission of $\mathrm{Ce}^{3+}$ and $\mathrm{Eu}^{2+}$ ions with allowed $4 \mathrm{f} \rightarrow 5 \mathrm{~d}$ transitions locate at lower energies in sulphides (in the visible (vis) region) than in fluorides and oxides (in the ultraviolet (UV) region), which promises $\mathrm{Ce}^{3+}$ and $\mathrm{Eu}^{2+}$ activated sulphides as efficient phosphors in white light-emitting diodes (LEDs) [51-53]. Specifically, the absorption of $\mathrm{Ce}^{3+}$ in alkaline-earth sulfides (e.g., $\mathrm{CaS}$ and $\mathrm{SrS}$ ) in the blue region of the spectrum matches well with the emission of the commercial blue-LED chip. This enables the development of blue-LEDexcitable NIR-II luminescent nanoprobes via energy transfer (ET) from $\mathrm{Ce}^{3+}$ to NIR-II $\mathrm{Ln}^{3+}$ emitters [46]. Moreover, owing to the strong CF level splitting, the luminescence of $\operatorname{Ln}^{3+}$ via $4 \mathrm{f} \rightarrow 4 \mathrm{f}$ transitions in the sulphide system is characterized by sharp CF emission peaks even at room temperature (RT), which may facilitate the devise of smart thermal sensors based on NIR-II

\footnotetext{
${ }^{1}$ College of Chemistry, Fuzhou University, Fuzhou 350116, China

${ }^{2}$ CAS Key Laboratory of Design and Assembly of Functional Nanostructures, Fujian Key Laboratory of Nanomaterials, and State Key Laboratory of Structural Chemistry, Fujian Institute of Research on the Structure of Matter, Chinese Academy of Sciences, Fuzhou 350002, China

${ }^{3}$ Fujian Science \& Technology Innovation Laboratory for Optoelectronic Information of China, Fuzhou 350108, China

* Corresponding authors (emails: zhengwei@fjirsm.ac.cn (Zheng W); xchen@fjirsm.ac.cn (Chen X))
} 
luminescence of $\mathrm{Ln}^{3+}$ from the thermally coupled CF levels $[54,55]$.

In this work, we develop a unique strategy for the controlled synthesis of $\mathrm{Ln}^{3+}$-doped SrS NCs via a high-temperature coprecipitation method. The optical properties, ET processes, and excited-state dynamics of $\mathrm{Ln}^{3+}$ in $\mathrm{Ce}^{3+}$ singly-doped, $\mathrm{Ce}^{3+} / \mathrm{Er}^{3+}$ and $\mathrm{Ce}^{3+} / \mathrm{Nd}^{3+}$ co-doped SrS NCs are systematically investigated through concentration- and temperature-dependent steady-state and transient PL spectroscopies. Through sensitization by $\mathrm{Ce}^{3+}$, efficient NIR-II luminescence from $\mathrm{Er}^{3+}$ and $\mathrm{Nd}^{3+}$ is achieved for the first time in sub-10 nm SrS NCs. Furthermore, by virtue of the well-resolved CF transition lines from ${ }^{4} \mathrm{I}_{13 / 2}$ of $\mathrm{Er}^{3+}$, we show the potential of SrS: $\mathrm{Ce}^{3+} / \mathrm{Er}^{3+} \mathrm{NCs}$ as blue-LED-excitable NIR-II luminescent nanoprobes for non-contact thermal sensing with a high sensitivity.

\section{EXPERIMENTAL SECTION}

\section{Chemicals and materials}

The metal acetates of $\mathrm{Sr}\left(\mathrm{CH}_{3} \mathrm{COO}\right)_{2} \cdot 0.5 \mathrm{H}_{2} \mathrm{O}$ (99.9\%), $\mathrm{Ce}\left(\mathrm{CH}_{3}-\right.$ $\mathrm{COO})_{3} \cdot 4 \mathrm{H}_{2} \mathrm{O}$ (99.99\%), $\mathrm{Er}\left(\mathrm{CH}_{3} \mathrm{COO}\right)_{3} \cdot 4 \mathrm{H}_{2} \mathrm{O} \quad(99.99 \%)$, and $\mathrm{Nd}\left(\mathrm{CH}_{3} \mathrm{COO}\right)_{3} \cdot 4 \mathrm{H}_{2} \mathrm{O}$ (99.99\%) were bought from Aladdin (China). The organic ligands of oleic acid (OA), oleylamine (OAm), 1-octadecene (ODE), and $N, N^{\prime}$-diphenylthiourea (DPTU) were purchased from Sigma-Aldrich (China). Ethanol and cyclohexane were bought from Sinopharm (China). All chemicals were used as received without further purification.

\section{Synthesis of SrS: $\operatorname{Ln}^{3+} \mathrm{NCs}$}

Monodispersed SrS: $\mathrm{Ln}^{3+} \mathrm{NCs}$ were prepared via a co-precipitation method at an elevated temperature. For synthesizing SrS: $0.1 \% \mathrm{Ce}^{3+} \mathrm{NCs}$, the metal acetates including $0.999 \mathrm{mmol}$ of $\mathrm{Sr}\left(\mathrm{CH}_{3} \mathrm{COO}\right)_{2} \cdot \mathrm{H}_{2} \mathrm{O}$ and $0.001 \mathrm{mmol}$ of $\mathrm{Ce}\left(\mathrm{CH}_{3} \mathrm{COO}\right)_{3} \cdot 4 \mathrm{H}_{2} \mathrm{O}$ $\left(0.01 \mathrm{~mol} \mathrm{~L}^{-1}\right.$ in aqueous solution, $\left.100 \mu \mathrm{L}\right)$ were first loaded into a $100-\mathrm{mL}$ three-necked flask, followed by addition of organic ligands containing $4 \mathrm{~mL}$ of $\mathrm{OA}, 8 \mathrm{~mL}$ of $\mathrm{OAm}$, and $8 \mathrm{~mL}$ of ODE. Then, the temperature was raised up to $120^{\circ} \mathrm{C}$ and the mixture was stirred at this temperature for $1 \mathrm{~h}$ under flowing with $\mathrm{N}_{2}$ to remove the residual water and oxygen. Thereafter, the temperature was raised up to $180^{\circ} \mathrm{C}$ and kept for $30 \mathrm{~min}$ to dissolve the metal acetates. The solution was then cooled down to RT and $3 \mathrm{mmol}$ of DPTU (in $10 \mathrm{~mL}$ of ethanol) was added. After evaporation of ethanol at $80^{\circ} \mathrm{C}$ for $30 \mathrm{~min}$, the solution was heated to $320^{\circ} \mathrm{C}$ and stirred for $1 \mathrm{~h}$ under $\mathrm{N}_{2}$ flow to complete the reaction. The resulting mixture was then cooled down to RT and $30 \mathrm{~mL}$ of ethanol was added to precipitate the products. The NCs were collected by centrifugation at $8000 \times \mathrm{g}$ for $6 \mathrm{~min}$, and then washed with ethanol and cyclohexane (2:1 in volume) twice. The powder samples were obtained by drying the colloidal $\mathrm{NCs}$ at $60^{\circ} \mathrm{C}$ in a vacuum drying oven for $12 \mathrm{~h}$.

\section{Characterizations}

Powder X-ray diffraction (XRD) measurement was performed on the MiniFlex $600 \mathrm{X}$-ray diffractometer (Rigaku) by using $\mathrm{Cu}$ $\operatorname{Kal}(\lambda=0.154187 \mathrm{~nm})$ as the radiation source. Transmission electron microscopy (TEM) images were acquired on a TECNAI G2 F20 TEM instrument. Inductively coupled plasma-atomic emission spectroscopy (ICP-AES, Ultima2, Jobin Yvon) and energy dispersive X-ray (EDX) spectrometer were used for the chemical composition analysis. The diffuse reflectance spectra were recorded on a UV/Vis/NIR spectrometer (Lambda 950,
Perkin-Elmer) and $\mathrm{BaSO}_{4}$ was used as the reference. The FLS980 spectrometer (Edinburgh) was employed for recording the PL excitation and emission spectra and PL decay curves of the samples. A continuous and pulsed xenon lamp (450 W) was used as the excitation source. For absolute PL quantum yield (QY) measurement, the standard barium sulfate-coated integrating sphere ( $150 \mathrm{~nm}$ in diameter, Edinburgh) was mounted on the FLS980 spectrometer and utilized as the sample chamber. The measurements were repeated for three times to produce the average value and standard deviation. For low-temperature PL measurements, a closed cycle cryostat (10-300 K, DE202, Advanced Research Systems) was used as the sample chamber, and the slits of excitation and emission monochromators were set as small as possible to maximize the instrumental resolution. All the spectral data were recorded at RT by using the powder samples unless otherwise noted and corrected for the spectral response of the instruments.

\section{RESULTS AND DISCUSSION}

The SrS crystal has a face-centered cubic structure (space group $F m \overline{3} \mathrm{~m}$ ) consisting of edge-sharing $\mathrm{SrS}_{6}$ octahedra (Fig. 1a) [56]. $\mathrm{Ln}^{3+}$ ions occupy the octahedral $\mathrm{Sr}^{2+}$ site, with charge compensation by $\mathrm{S}^{2-}$ deficiency. Monodispersed SrS: $\mathrm{Ln}^{3+} \mathrm{NCs}(\mathrm{Ln}=\mathrm{Ce}$, $\mathrm{Nd}$, and Er) were synthesized through a modified high-temperature co-precipitation method as we previously reported [46]. The as-synthesized NCs were hydrophobic owing to oleic ligands anchored to the surface, and thus can be readily dispersed in nonpolar organic solvents such as cyclohexane, forming a transparent colloidal solution. Upon doping with a trace amount $(0.1 \mathrm{~mol} \%)$ of $\mathrm{Ce}^{3+}$, the NCs exhibited bright bluegreen PL under 365-nm UV LED irradiation. XRD patterns of the NCs (Fig. 1b) display intense diffraction peaks which match well with cubic SrS (JCPDS No. 008-0489), indicating high crystallinity and phase purity of the resulting NCs. The diffraction peaks of the NCs turn broader with increasing $\mathrm{Ln}^{3+}$ doping concentration (Fig. S1), suggesting a size reduction of the NCs induced by $\mathrm{Ln}^{3+}$ doping. According to the Debye-Scherrer equation, the mean sizes of the NCs were estimated to be $10.9 \pm$ $0.4,10.4 \pm 0.7,9.6 \pm 0.3$, and $9.9 \pm 0.6 \mathrm{~nm}$ for $\mathrm{SrS}, \mathrm{SrS}: 0.1 \% \mathrm{Ce}^{3+}$, SrS: $0.1 \% \mathrm{Ce}^{3+} / 0.5 \% \mathrm{Er}^{3+}$, and $\mathrm{SrS}: 0.1 \% \mathrm{Ce}^{3+} / 0.2 \% \mathrm{Nd}^{3+}$, respectively. Such a size reduction induced by $\mathrm{Ln}^{3+}$ doping can be ascribed to the charge compensation by extra $S^{2-}$ which introduced transient electric dipoles to the NC surface with negative poles outwards. These transient electric dipoles hindered the diffusion of $\mathrm{S}^{2-}$ ions from the solution to the grain surface, thus retarding the growth of SrS NCs [57]. TEM images show that the NCs are monodispersed and roughly spherical with mean sizes of $10.4 \pm 1.1,10.4 \pm 0.9,9.5 \pm 0.9$, and $9.7 \pm 0.9 \mathrm{~nm}$ for $\mathrm{SrS}$, SrS: $0.1 \% \mathrm{Ce}^{3+}, \mathrm{SrS}: 0.1 \% \mathrm{Ce}^{3+} / 0.5 \% \mathrm{Er}^{3+}$, and $\mathrm{SrS}: 0.1 \% \mathrm{Ce}^{3+} / 0.2 \%$ $\mathrm{Nd}^{3+} \mathrm{NCs}$, respectively (Fig. $1 \mathrm{c}-\mathrm{f}$ and Fig. S2), in good agreement with those determined by XRD measurements. The representative high-resolution TEM (HRTEM) image of the NCs (inset of Fig. 1c) exhibits clear lattice fringes with an observed d spacing of $0.21 \mathrm{~nm}$, corresponding to the (220) plane of cubic SrS. The selected-area electron diffraction (SAED) pattern of the NCs shows intense diffraction rings that can be well indexed into cubic SrS (inset of Fig. 1f). Composition analyses through EDX spectrum and ICP-AES identify the elements of $\mathrm{Sr}$ and $\mathrm{S}$ and $0.13 \mathrm{~mol} \%$ of $\mathrm{Ce}^{3+}$ dopants in SrS: $0.1 \% \mathrm{Ce}^{3+} \mathrm{NCs}$ (Fig. S3). All these results reveal high quality of the as-synthesized $\mathrm{Ln}^{3+}$-doped SrS NCs. 

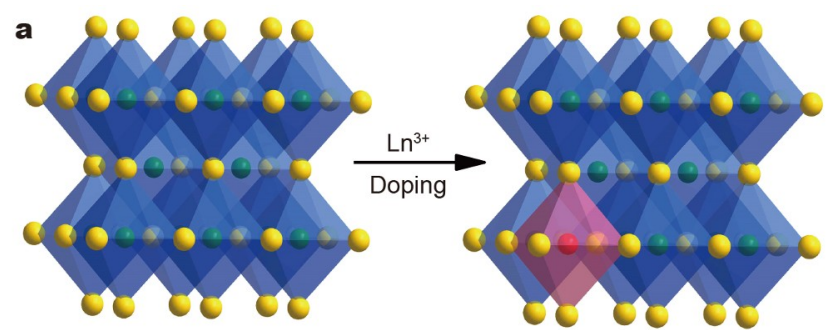

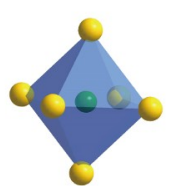

$\left[\mathrm{SrS}_{6}\right]^{10-}$
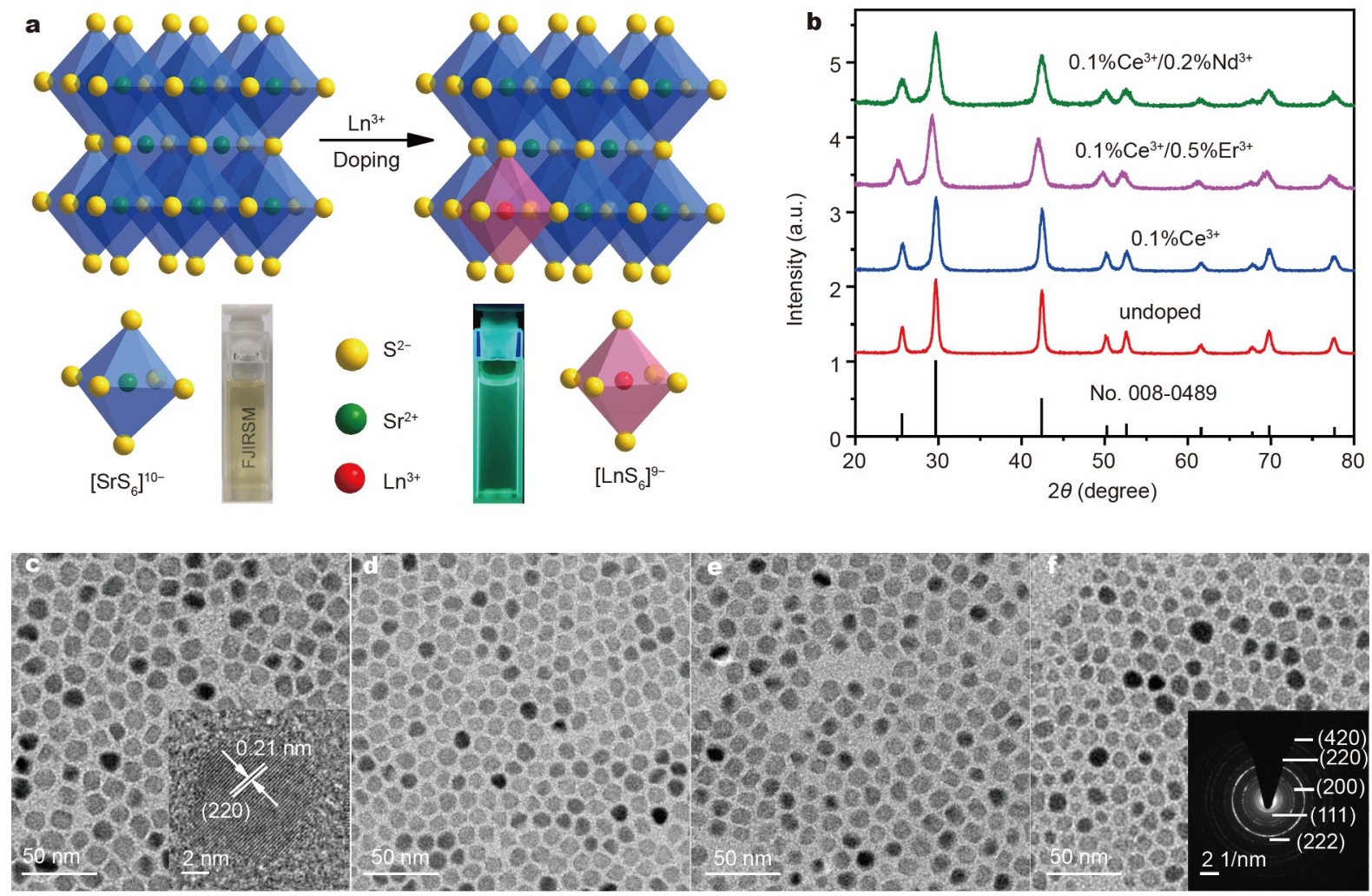

Figure 1 (a) Arrangement of strontium and sulphur atoms in the SrS structure and the crystallographic site for $\mathrm{Ln}^{3+}$ dopants. The photographs for the cyclohexane solution $\left(1 \mathrm{mg} \mathrm{mL}^{-1}\right)$ of $\mathrm{SrS}: 0.1 \% \mathrm{Ce}^{3+} \mathrm{NCs}$ under (left) ambient light and (right) $365-\mathrm{nm}$ UV light are presented, showing transparency of the

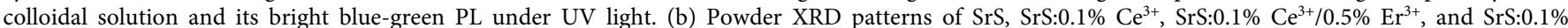
$\mathrm{Ce}^{3+} / 0.2 \% \mathrm{Nd}^{3+} \mathrm{NCs}$. The vertical lines in the bottom represent the standard pattern of cubic SrS (JCPDS No. 008-0489). TEM images of (c) SrS, (d) SrS:0.1\% $\mathrm{Ce}^{3+}$, (e) SrS: $0.1 \% \mathrm{Ce}^{3+} / 0.5 \% \mathrm{Er}^{3+}$, and (f) SrS: $0.1 \% \mathrm{Ce}^{3+} / 0.2 \% \mathrm{Nd}^{3+} \mathrm{NCs}$. The insets show the corresponding HRTEM image and SAED pattern of the NCs.

Optical absorption spectra show that the NCs have large absorbance in the UV region with a maximum at around $252 \mathrm{~nm}$ and a long absorption tail extending to $600 \mathrm{~nm}$ (Fig. S4). From the Tauc plot of the absorption spectra, the bandgap of the undoped SrS NCs was estimated to be $4.2 \mathrm{eV}$, which is generally consistent with that $(4.3 \mathrm{eV})$ of bulk SrS [58]. Upon $0.1 \mathrm{~mol} \%$ of $\mathrm{Ce}^{3+}$ doping, an additional absorption band at around $430 \mathrm{~nm}$ was explicitly observed, which can be assigned to the $4 \mathrm{f} \rightarrow 5 \mathrm{~d}$ transition of octahedral $\mathrm{Ce}^{3+}$ in SrS NCs [59]. Under excitation at $410 \mathrm{~nm}, \mathrm{Ce}^{3+}$ singly-doped NCs exhibited bright blue-green PL with two broad emission bands at 478 and $530 \mathrm{~nm}$ (Fig. 2a), corresponding to the electronic transitions of $\mathrm{Ce}^{3+}$ from the lowest ${ }^{2} \mathrm{~T}_{2 \mathrm{~g}}$ level of the $5 \mathrm{~d}$ state to the ${ }^{2} \mathrm{~F}_{5 / 2}$ and ${ }^{2} \mathrm{~F}_{7 / 2}$ levels of the $4 \mathrm{f}$ ground state, respectively [59]. By monitoring the $\mathrm{Ce}^{3+}$ emission at $530 \mathrm{~nm}$, two intense excitation bands at 263 and $430 \mathrm{~nm}$ were observed, ascribing to the host absorption of SrS and the $4 \mathrm{f} \rightarrow 5 \mathrm{~d}$ transition of $\mathrm{Ce}^{3+}$, respectively [53]. Furthermore, it was observed that the PL intensity of the NCs increased gradually with increasing $\mathrm{Ce}^{3+}$ concentration from 0.01 to $0.1 \mathrm{~mol} \%$ and then decreased at higher $\mathrm{Ce}^{3+}$ concentrations, indicative of an extremely low quenching concentration $(0.1 \mathrm{~mol} \%)$ of $\mathrm{Ce}^{3+}$ in SrS NCs. When the $\mathrm{Ce}^{3+}$ concentration exceeded $0.5 \mathrm{~mol} \%$, the emission bands of $\mathrm{Ce}^{3+}$ were red-shifted and broadened significantly, due to ET from $\mathrm{Ce}^{3+}$ ions emitting at higher energy to slightly perturbed $\mathrm{Ce}^{3+}$ ions emitting at lower energies [60], as also evidenced by the decreased PL lifetime of $\mathrm{Ce}^{3+}$ from $4.5 \mathrm{~ns}(0.1 \mathrm{~mol} \%)$ to $3.9 \mathrm{~ns}(1 \mathrm{~mol} \%)$ with increasing $\mathrm{Ce}^{3+}$ concentration (Fig. $2 \mathrm{~b}$ and Table S1). The absolute PLQY was determined to be $6.1 \% \pm 0.1 \%$ for SrS: $0.1 \% \mathrm{Ce}^{3+} \mathrm{NCs}$, which is higher than that $(2.9 \%)$ of $10.2-\mathrm{nm} \mathrm{CaS}: \mathrm{Ce}^{3+} \mathrm{NCs}$ we previously reported [46]. In comparison with $\mathrm{CaS}$, the $\mathrm{SrS}$ host exerts weaker covalency and CF strength on $\mathrm{Ce}^{3+}$ ions due to the higher metallicity of $\mathrm{Sr}^{2+}$ than $\mathrm{Ca}^{2+}$. Therefore, the $5 \mathrm{~d}$ state of $\mathrm{Ce}^{3+}$ locates at higher energies in $\mathrm{SrS}$ than in $\mathrm{CaS}$, which results in a blueshift in the emission bands of $\mathrm{Ce}^{3+}(478$ and $530 \mathrm{~nm})$ in $\mathrm{SrS}$ relative to that $(505$ and $565 \mathrm{~nm})$ in CaS (Fig. S5). As such, $\mathrm{Ce}^{3+}$ ions are less affected by the surface quenching effect and have a higher PLQY in SrS NCs than in CaS NCs with a similar size.

Fig. 2c and Fig. S6 show the temperature-dependent PL emission spectra $(10-300 \mathrm{~K})$ of $\mathrm{SrS}: 0.1 \% \mathrm{Ce}^{3+} \mathrm{NCs}$ under excitation at $410 \mathrm{~nm}$. The PL intensity of the NCs decreased gradually with the temperature rises due to the accelerated nonradiative relaxation and enhanced electron-phonon coupling of $\mathrm{Ce}^{3+}$ at higher temperatures [61], as further verified by the decreased PL lifetime of $\mathrm{Ce}^{3+}$ from 9.1 to $5.0 \mathrm{~ns}$ with elevating the temperature from 10 to $300 \mathrm{~K}$ (Fig. S7 and Table S2). Based on the Arrhenius plot of the integrated PL intensity of $\mathrm{Ce}^{3+}$ versus the inverse temperature (Fig. 2d) [62]:

$I(T)=\frac{I_{0}}{1+A \exp \left(-E_{\mathrm{a}} / k_{\mathrm{B}} T\right)}$,

where $I(T)$ and $I_{0}$ are the integrated PL intensities at $T$ and $0 \mathrm{~K}$, respectively, $E_{\mathrm{a}}$ is the activation energy, and $k_{\mathrm{B}}$ is the Boltzman constant. The activation energy was determined to be $54.6 \mathrm{meV}$. The relatively small activation energy of $\mathrm{Ce}^{3+}$ in SrS NCs, along 

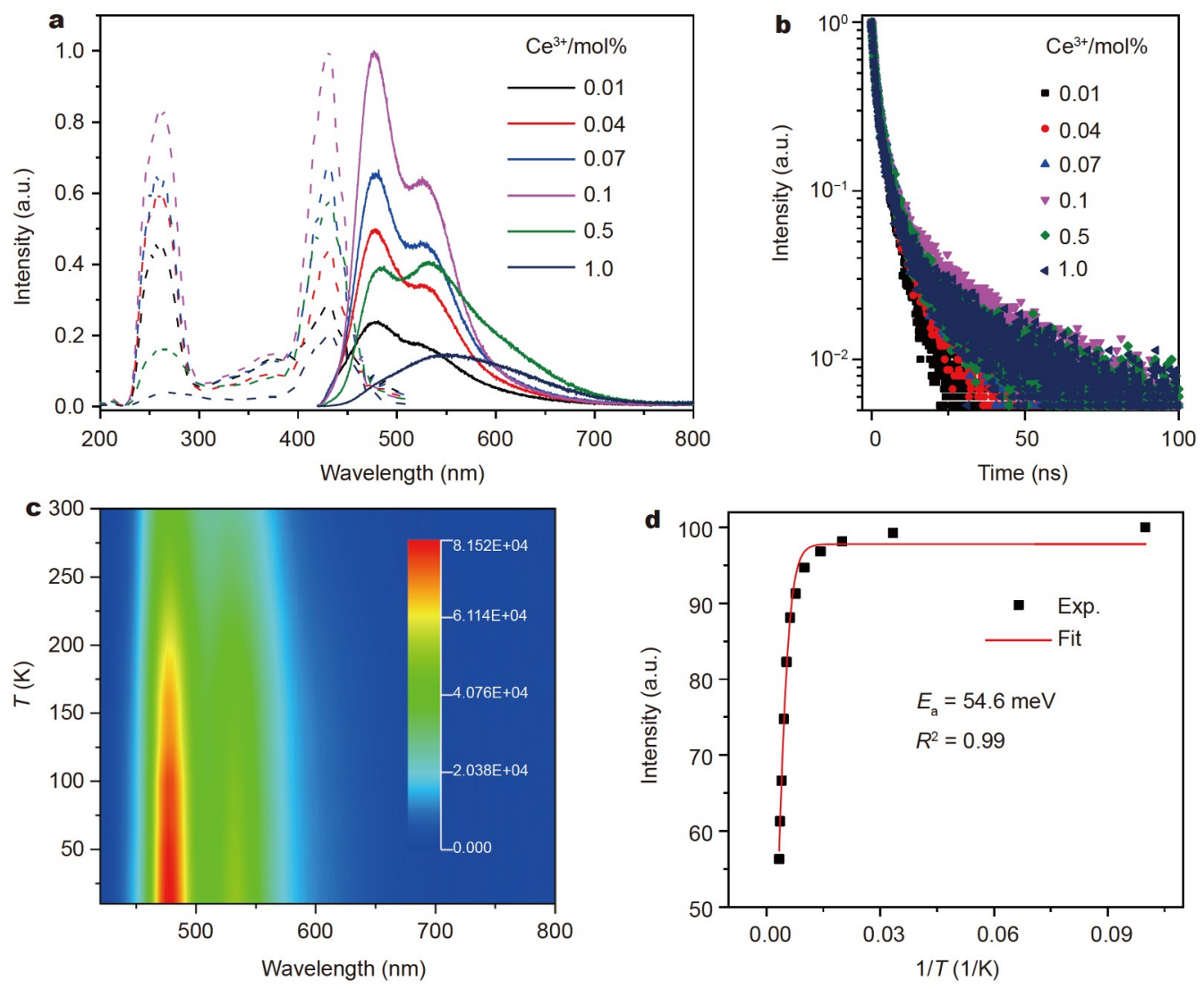

Figure 2 (a) PL excitation spectra (dash line, $\lambda_{\mathrm{em}}=530 \mathrm{~nm}$ ), PL emission spectra (solid line, $\lambda_{\mathrm{ex}}=410 \mathrm{~nm}$ ), and (b) PL decay curves $\left(\lambda_{\mathrm{em}}=530 \mathrm{~nm}\right)$ of SrS: $x \%$ $\mathrm{Ce}^{3+}$ NCs with different $\mathrm{Ce}^{3+}$ concentrations. (c) Wavelength-temperature contour plot of the temperature-dependent PL emission spectra of SrS:0.1\% Ce $\mathrm{e}^{3+}$ NCs under excitation at $410 \mathrm{~nm}$. (d) Integrated PL intensity for the $\mathrm{Ce}^{3+}$ emission as a function of temperature, whereby the activation energy $\left(E_{\mathrm{a}}\right)$ for the Ce $\mathrm{e}^{3+}$ emission in $\mathrm{SrS}: 0.1 \% \mathrm{Ce}^{3+} \mathrm{NCs}$ was derived.

with the high covalency and volatility of $\mathrm{S}^{2-}$ which result in abundant $S^{2-}$ deficiency in the NCs [63], may account for the low quenching concentration $(0.1 \mathrm{~mol} \%)$ of $\mathrm{Ce}^{3+}$ in SrS NCs.

In addition to that of $\mathrm{Ce}^{3+}$ singly-doped SrS NCs, we also investigated the optical properties of $\mathrm{Ce}^{3+} / \mathrm{Nd}^{3+}$ and $\mathrm{Ce}^{3+} / \mathrm{Er}^{3+}$ co-doped SrS NCs. As shown in Fig. 3a, upon excitation to the $\mathrm{Ce}^{3+} 5 \mathrm{~d}$ state at $430 \mathrm{~nm}$, characteristic and sharp emission peaks from the ${ }^{4} \mathrm{~F}_{3 / 2} \rightarrow{ }^{4} \mathrm{I}_{J}$ transitions of $\mathrm{Nd}^{3+}$ in NIR-I $(700-950 \mathrm{~nm})$ at $890 \mathrm{~nm}\left({ }^{4} \mathrm{I}_{9 / 2}\right)$ and NIR-II at $1081 \mathrm{~nm}\left({ }^{4} \mathrm{I}_{11 / 2}\right)$ and $1354 \mathrm{~nm}\left({ }^{4} \mathrm{I}_{13 / 2}\right)$ were detected in $\mathrm{Ce}^{3+} / \mathrm{Nd}^{3+}$ co-doped SrS NCs, along with the blue-green emission of $\mathrm{Ce}^{3+}$ at 478 and $530 \mathrm{~nm}$. The PL intensity of $\mathrm{Nd}^{3+}$ increased gradually with increasing $\mathrm{Nd}^{3+}$ concentrations from 0 to $0.2 \mathrm{~mol} \%$ and then decreased at higher $\mathrm{Nd}^{3+}$ concentrations owing to the concentration quenching effect [64], with the effective PL lifetime of $\mathrm{Nd}^{3+}$ decreasing from $3.6 \mathrm{~ms}$

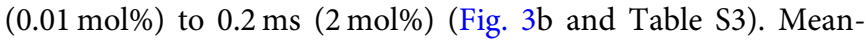
while, the PL intensity of $\mathrm{Ce}^{3+}$ decreased significantly with increasing $\mathrm{Nd}^{3+}$ concentration, indicating an efficient ET from $\mathrm{Ce}^{3+}$ to $\mathrm{Nd}^{3+}$ in the NCs. Such Ce ${ }^{3+}$-to- $\mathrm{Nd}^{3+}$ ET was further confirmed by the nearly identical excitation bands for the $\mathrm{Ce}^{3+}$ and $\mathrm{Nd}^{3+}$ emissions and the decreased PL lifetime of $\mathrm{Ce}^{3+}$ from 4.5 to $3.1 \mathrm{~ns}$ when the $\mathrm{Nd}^{3+}$ concentration increased from 0 to $2 \mathrm{~mol} \%$ (Fig. 3c, d). From the PL lifetime of $\mathrm{Ce}^{3+}$, the efficiency of $\mathrm{ET}$ from $\mathrm{Ce}^{3+}$ to $\mathrm{Nd}^{3+}$ was calculated, with the highest value of $31.1 \%$ in SrS:0.1\% $\mathrm{Ce}^{3+} / 2 \% \mathrm{Nd}^{3+} \mathrm{NCs}$ (Table S3). Fig. 3e depicts the ET processes from $\mathrm{Ce}^{3+}$ to $\mathrm{Nd}^{3+}$ in SrS NCs. Upon excitation at $430 \mathrm{~nm}$, the $\mathrm{Ce}^{3+}$ ion is excited to the $5 \mathrm{~d}$ state, and then ET occurs from the lowest ${ }^{2} \mathrm{~T}_{2 \mathrm{~g}}$ level of the Ce ${ }^{3+} 5 \mathrm{~d}$ state to the ${ }^{4} \mathrm{G}_{5 / 2} /$ ${ }^{4} \mathrm{G}_{7 / 2}$ levels of $\mathrm{Nd}^{3+}$, followed by nonradiative relaxation to ${ }^{4} \mathrm{~F}_{3 / 2}$ of $\mathrm{Nd}^{3+}$ which results in intense NIR emission of $\mathrm{Nd}^{3+}$ through ${ }^{4} \mathrm{~F}_{3 / 2} \rightarrow{ }^{4} \mathrm{I}_{J}(J=9 / 2,11 / 2$, and 13/2) transitions.

Similarly, upon excitation at $430 \mathrm{~nm}$, both the $\mathrm{Ce}^{3+}$ emission at 478 and $530 \mathrm{~nm}$ and the typical NIR-II emission from the ${ }^{4} \mathrm{I}_{13 / 2}$ $\rightarrow{ }^{4} \mathrm{I}_{15 / 2}$ transition of $\mathrm{Er}^{3+}$ at $1539 \mathrm{~nm}$ were observed in $\mathrm{Ce}^{3+} / \mathrm{Er}^{3+}$ co-doped SrS NCs (Fig. 4a). The PL intensity of $\mathrm{Er}^{3+}$ underwent a gradual increase with increasing $\mathrm{Er}^{3+}$ concentration from 0.01 to $0.5 \mathrm{~mol} \%$ and then decreased at higher $\mathrm{Er}^{3+}$ concentrations at the expense of $\mathrm{Ce}^{3+}$ emission, as a result of efficient ET from $\mathrm{Ce}^{3+}$ to $\mathrm{Er}^{3+}$. Accordingly, the effective PL lifetimes of $\mathrm{Er}^{3+}$ and $\mathrm{Ce}^{3+}$ decreased from $13.0 \mathrm{~ms}(0.01 \mathrm{~mol} \%)$ and $4.5 \mathrm{~ns}$ to $0.3 \mathrm{~ms}$ and $2.3 \mathrm{~ns}$, respectively, as the $\mathrm{Er}^{3+}$ concentration increased from 0 to $5 \mathrm{~mol} \%$ (Fig. $4 \mathrm{~b}, \mathrm{c}$ ), due to the concentration quenching effect of $\mathrm{Er}^{3+}$ and $\mathrm{Ce}^{3+}$-to-Er ${ }^{3+}$ ET. PL excitation spectra of the NCs by monitoring the $\mathrm{Er}^{3+}$ emission at $1539 \mathrm{~nm}$ and the $\mathrm{Ce}^{3+}$ emission at $530 \mathrm{~nm}$ exhibited nearly identical excitation bands from the host absorption of SrS and the $4 \mathrm{f} \rightarrow 5 \mathrm{~d}$ transition of $\mathrm{Ce}^{3+}$ (Fig. 4d), confirming the efficient $\mathrm{Ce}^{3+}-$ to- $^{3+} \mathrm{r}^{3+}$ ET. From the PL lifetime of $\mathrm{Ce}^{3+}$, the efficiency of ET from $\mathrm{Ce}^{3+}$ to $\mathrm{Er}^{3+}$ was calculated, with the highest value of $48.9 \%$ in SrS: $0.1 \% \mathrm{Ce}^{3+} / 5 \%$ $\mathrm{Er}^{3+}$ NCs (Table S4). By contrast, negligibly weak PL was detected in $\mathrm{Er}^{3+}$ (or $\mathrm{Nd}^{3+}$ ) singly-doped SrS NCs. These results demonstrate unambiguously that it is the allowed $4 \mathrm{f} \rightarrow 5 \mathrm{~d}$ tran- 

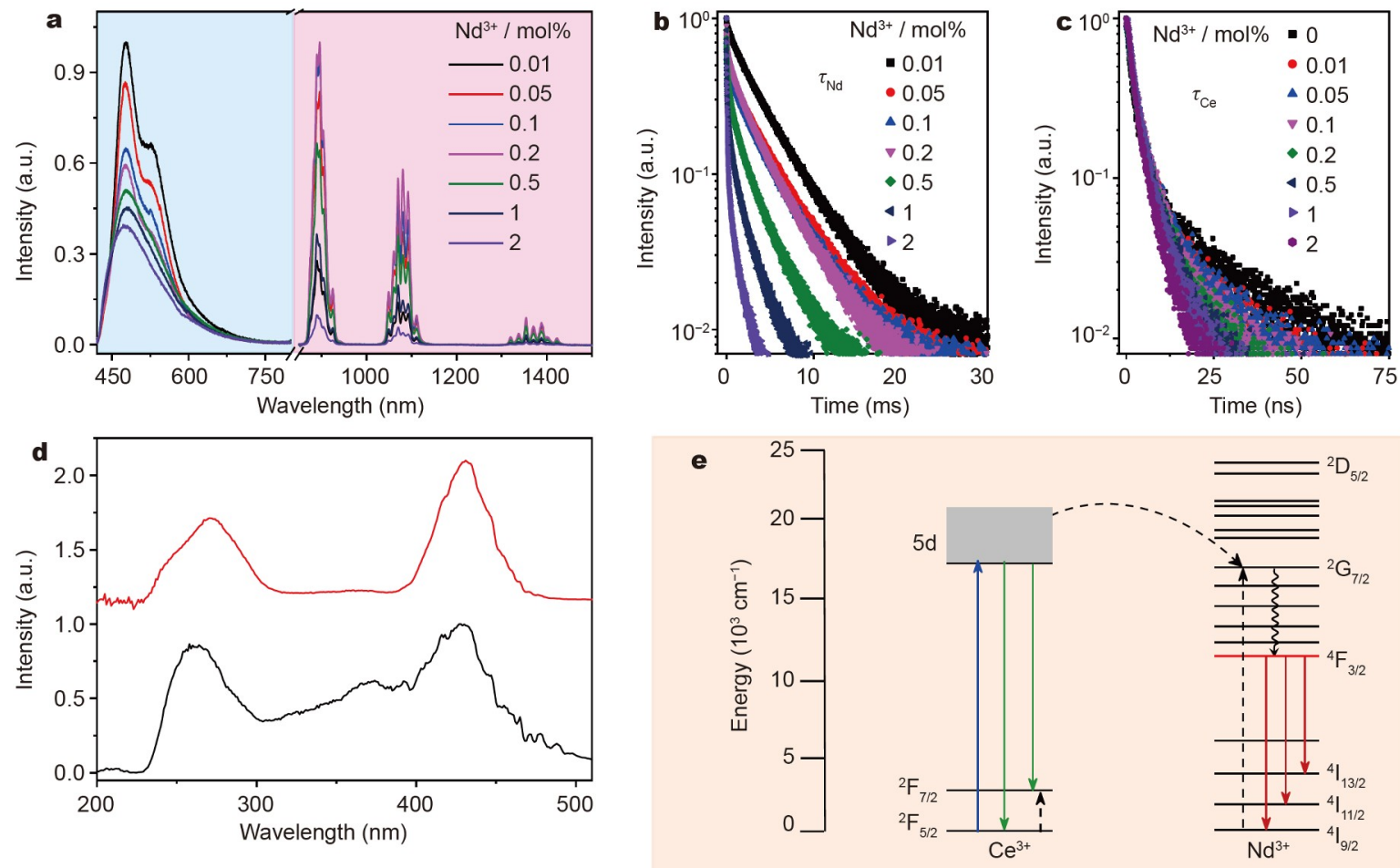

Figure 3 (a) $\mathrm{Nd}^{3+}$ concentration-dependent PL emission spectra $\left(\lambda_{\mathrm{ex}}=430 \mathrm{~nm}\right)$, and PL decay curves from (b) ${ }^{4} \mathrm{~F}_{3 / 2}$ level of Nd ${ }^{3+}\left(\lambda_{\text {em }}=1081 \mathrm{~nm}\right)$ and $(\mathrm{c}) 5 \mathrm{~d}$ state of $\mathrm{Ce}^{3+}\left(\lambda_{\mathrm{em}}=530 \mathrm{~nm}\right)$ in SrS: $0.1 \% \mathrm{Ce}^{3+} / x \% \mathrm{Nd}^{3+} \mathrm{NCs}$. (d) PL excitation spectra of $\mathrm{SrS}: 0.1 \% \mathrm{Ce}^{3+} / 0.2 \% \mathrm{Nd}^{3+} \mathrm{NCs}$ by monitoring the Ce ${ }^{3+}\left(\right.$ black) and $\mathrm{Nd}^{3+}$ (red) emissions at 530 and $1081 \mathrm{~nm}$, respectively, showing the typical excitation bands from the host absorption of SrS and the $4 \mathrm{f} \rightarrow 5 \mathrm{~d}$ transition of Ce $\mathrm{C}^{3+}$ for

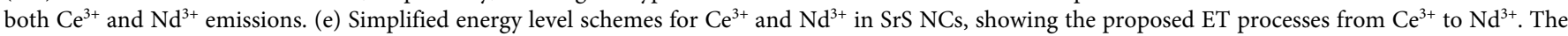
dashed, curve, and full arrows represent the ET, nonradiative relaxation and radiative transition processes, respectively.

sition of $\mathrm{Ce}^{3+}$ which harvests the excitation light and then sensitizes the NIR-II luminescence of $\mathrm{Er}^{3+}$ and $\mathrm{Nd}^{3+}$ in $\mathrm{Ce}^{3+} / \mathrm{Er}^{3+}$ and $\mathrm{Ce}^{3+} / \mathrm{Nd}^{3+}$ co-doped SrS NCs. As illustrated in Fig. 4e, upon excitation to the $5 \mathrm{~d}$ state of $\mathrm{Ce}^{3+}$, the excitation energy is transferred from the lowest ${ }^{2} \mathrm{~T}_{2 \mathrm{~g}}$ level of $\mathrm{Ce}^{3+}$ to the ${ }^{2} \mathrm{H}_{11 / 2} /{ }^{4} \mathrm{~S}_{3 / 2}$ levels of $\mathrm{Er}^{3+}$, followed by nonradiative (or radiative) relaxation to ${ }^{4} \mathrm{I}_{13 / 2}$ of $\mathrm{Er}^{3+}$ which leads to intense NIR-II emission of $\mathrm{Er}^{3+}$ through ${ }^{4} \mathrm{I}_{13 / 2} \rightarrow{ }^{4} \mathrm{I}_{15 / 2}$ transition. The PLQYs for the NIR-II emissions of $\mathrm{Er}^{3+}$ and $\mathrm{Nd}^{3+}$ sensitized by $\mathrm{Ce}^{3+}$ were estimated to be $2.9 \% \pm 0.1 \%$ in $\mathrm{SrS}: 0.1 \% \mathrm{Ce}^{3+} / 0.5 \% \mathrm{Er}^{3+}$ and $2.3 \% \pm 0.1 \%$ in SrS: $0.1 \% \mathrm{Ce}^{3+} / 0.2 \% \mathrm{Nd}^{3+} \mathrm{NCs}$. It is worth mentioning that, despite its currently low internal PLQYs, the NIR-II PL of $\mathrm{Er}^{3+}$ and $\mathrm{Nd}^{3+}$ sensitized by the allowed $4 \mathrm{f} \rightarrow 5 \mathrm{~d}$ transition of $\mathrm{Ce}^{3+}$ in SrS NCs is much stronger than that in fluorides such as $\mathrm{NaYF}_{4}$ : $\mathrm{Yb}^{3+} / \mathrm{Er}^{3+} \mathrm{NCs}$ via excitation based on the forbidden $4 \mathrm{f} \rightarrow 4 \mathrm{f}$ transitions.

To gain deep insights into the ET processes from $\mathrm{Ce}^{3+}$ to $\mathrm{Er}^{3+}$ and $\mathrm{Nd}^{3+}$ in $\mathrm{Ce}^{3+} / \mathrm{Er}^{3+}$ and $\mathrm{Ce}^{3+} / \mathrm{Nd}^{3+}$ co-doped $\mathrm{SrS} \mathrm{NCs}$, we carried out temperature-dependent steady-state and transient PL spectroscopic measurements. Fig. 5a shows the temperaturedependent PL emission spectra $(10-300 \mathrm{~K})$ of $\mathrm{SrS}: 0.1 \%$ $\mathrm{Ce}^{3+} / 0.5 \% \mathrm{Er}^{3+} \mathrm{NCs}$ under excitation at $430 \mathrm{~nm}$. It was observed that the integrated PL intensity and PL lifetime for the bluegreen emission of $\mathrm{Ce}^{3+}$ decreased gradually with increasing the temperature from 10 to $300 \mathrm{~K}$ (Fig. S8 and Table S5), due mainly to larger nonradiative transition probability of $\mathrm{Ce}^{3+}$ at higher temperatures, as also observed in $\mathrm{Ce}^{3+}$ singly-doped SrS NCs. For comparison, the integrated PL intensity for the NIR-II emission of $\mathrm{Er}^{3+}$ exhibited a slight decrease with increasing temperature from 10 to $100 \mathrm{~K}$ and then increased steadily with the temperature rise (Fig. 5b), in parallel with the essentially unchanged PL lifetime of $6.5 \mathrm{~ms}$ (Fig. S9). Such a temperature evolution in PL intensity and PL lifetime of $\mathrm{Er}^{3+}$ in $\mathrm{SrS}: \mathrm{Ce}^{3+} / \mathrm{Er}^{3+}$ $\mathrm{NCs}$ was different from those of $\mathrm{Nd}^{3+}$ in $\mathrm{SrS}: \mathrm{Ce}^{3+} / \mathrm{Nd}^{3+} \mathrm{NCs}$, wherein both the PL intensities and PL lifetimes of $\mathrm{Ce}^{3+}$ and $\mathrm{Nd}^{3+}$ decreased significantly with the temperature rise (Fig. S10 and Table S6). This implies a phonon-assisted ET process from $\mathrm{Ce}^{3+}$ to $\mathrm{Er}^{3+}$ in $\mathrm{SrS}: \mathrm{Ce}^{3+} / \mathrm{Er}^{3+} \mathrm{NCs}$, in view of the increased occupation number of the phonon state at higher temperatures [65].

Coincidently, we found that the intensities for the ${ }^{4} \mathrm{I}_{13 / 2} \rightarrow{ }^{4} \mathrm{I}_{15 / 2}$ CF transition lines of $\mathrm{Er}^{3+}$ experienced drastically distinct temperature dependence. Because of the increased occupation number of the phonon state at higher temperatures, the highlying CF sublevel $\left(\mathrm{R}_{2}\right)$ of ${ }^{4} \mathrm{I}_{13 / 2}$ of $\mathrm{Er}^{3+}$ will be thermally populated from the low-lying one $\left(\mathrm{R}_{1}\right)$ with increasing temperature [54]. As a result, the intensities for the CF transitions of $\mathrm{Er}^{3+}$ from $\mathrm{R}_{2}$ of ${ }^{4} \mathrm{I}_{13 / 2}$ to the higher-lying CF sublevels of ${ }^{4} \mathrm{I}_{15 / 2}$ at 1551 and $1554 \mathrm{~nm}$ showed an increase with the temperature rise, whereas those from $\mathrm{R}_{1}$ of ${ }^{4} \mathrm{I}_{13 / 2}$ to the lower-lying CF sublevels of ${ }^{4} \mathrm{I}_{15 / 2}$ at $1534,1539,1541$, and $1544 \mathrm{~nm}$ decreased (inset of Fig. 5a). It is difficult to accurately identify all the ${ }^{4} \mathrm{I}_{13 / 2} \rightarrow{ }^{4} \mathrm{I}_{15 / 2}$ CF transition lines of $\mathrm{Er}^{3+}$ in SrS NCs, because of the negligibly weak PL upon direct excitation to $\mathrm{Er}^{3+}$ based on the forbidden $4 \mathrm{f} \rightarrow 4 \mathrm{f}$ transitions. Nonetheless, the CF emission peaks of $\mathrm{Er}^{3+}$ at 1539 and $1554 \mathrm{~nm}$, which exhibit opposite temperature dependence in intensity (Fig. 5c), are sharp and well-resolved with little interference from other Stark components at temperatures below 

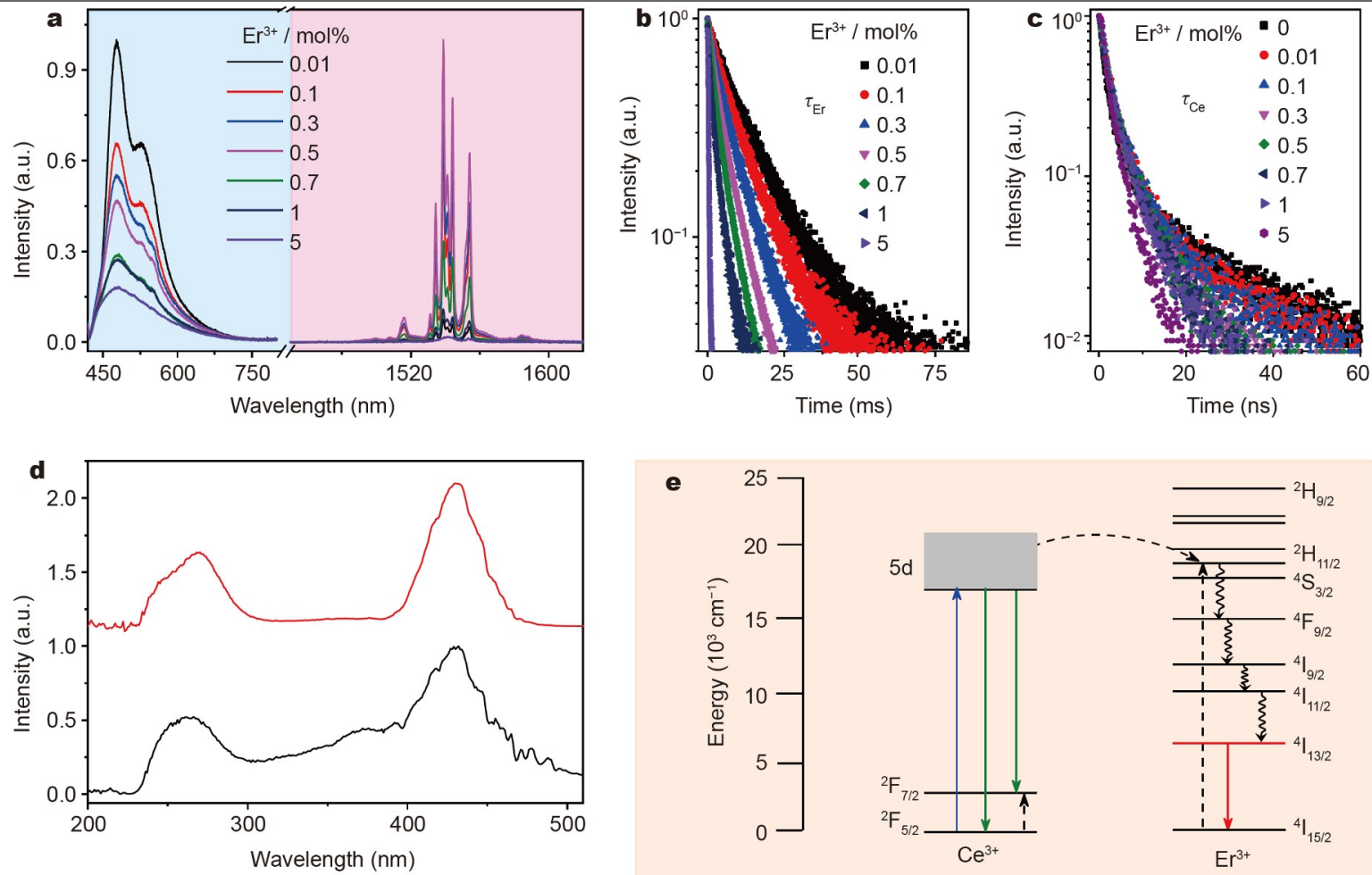

Figure 4 (a) $\mathrm{Er}^{3+}$ concentration-dependent PL emission spectra $\left(\lambda_{\mathrm{ex}}=430 \mathrm{~nm}\right)$, and PL decay curves from (b) ${ }^{4} \mathrm{I}_{13 / 2}$ level of $\mathrm{Er}^{3+}\left(\lambda_{\mathrm{em}}=1539 \mathrm{~nm}\right)$ and $(\mathrm{c}) 5 \mathrm{~d}$ state of $\mathrm{Ce}^{3+}\left(\lambda_{\mathrm{em}}=530 \mathrm{~nm}\right)$ in SrS: $0.1 \% \mathrm{Ce}^{3+} / x \% \mathrm{Er}^{3+}$ NCs. (d) PL excitation spectra of SrS: $0.1 \% \mathrm{Ce}^{3+} / 0.5 \% \mathrm{Er}^{3+} \mathrm{NCs}_{\text {by monitoring the Ce }}{ }^{3+}(\mathrm{black})$ and $\mathrm{Er}^{3+}$ (red) emissions at 530 and $1539 \mathrm{~nm}$, respectively, showing the typical excitation bands from the host absorption of SrS and the $4 \mathrm{f} \rightarrow 5 \mathrm{~d}$ transition of Ce $\mathrm{e}^{3+}$ for

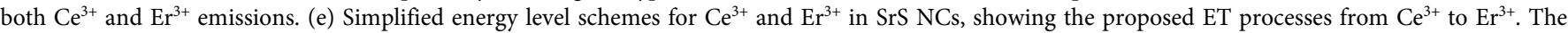
dashed, curve, and full arrows represent the ET, nonradiative relaxation and radiative transition processes, respectively.

$300 \mathrm{~K}$. This feature makes SrS: $\mathrm{Ce}^{3+} / \mathrm{Er}^{3+} \mathrm{NCs}$ an ideal nanoprobe candidate for ratiometric temperature sensing based on the temperature-dependent fluorescent intensity ratio (FIR) of $\mathrm{Er}^{3+}$ at 1554 and $1539 \mathrm{~nm}\left(I_{1554} / I_{1539}\right)$.

As shown in Fig. 5 d, the FIR of $I_{1554} / I_{1539}$ increased remarkably from 0.17 to 0.60 with increasing the temperature from 10 to $300 \mathrm{~K}$, as a result of enhanced thermal population of the $R_{2}$ sublevel from $\mathrm{R}_{1}$ of ${ }^{4} \mathrm{I}_{13 / 2}$ of $\mathrm{Er}^{3+}$ at higher temperatures. According to the theory of Boltzmann distribution, the FIR of the thermally coupled Stark sublevels $\left(R_{1}\right.$ and $\left.R_{2}\right)$ of ${ }^{4} I_{13 / 2}$ can be expressed as [66]

$\mathrm{FIR}=\frac{I_{1554}}{I_{1539}}=C \exp \left(-\frac{\Delta E}{k_{\mathrm{B}} T}\right)$,

where $C$ is a constant dictated by the radiative transition rates, degeneracies and the emission cross-sections of $R_{1}$ and $R_{2}$ sublevels, and $\Delta E$ represents the energy gap between $\mathrm{R}_{1}$ and $\mathrm{R}_{2}$. As a consequence, the natural logarithm of the FIR displayed a linear relationship with the inverse temperature (Fig. 5e). By linear fitting to the plot, the energy gap $\Delta E$ and the constant $C$ were calculated to be $87.7 \mathrm{~cm}^{-1}$ and 0.90 , respectively. The temperature sensitivity $(S)$ of the nanoprobes, defined as the rate of FIR change versus temperature change, is expressed as [67]

$S(T)=\frac{\mathrm{d}(\mathrm{FIR})}{\mathrm{d} T}=C\left(\frac{\Delta E}{k_{\mathrm{B}} T^{2}}\right) \exp \left(-\frac{\Delta E}{k_{\mathrm{B}} T}\right)$.

By taking the values of $C$ and $\Delta E$ into Equation (3), the sensitivity function $S(T)$ versus $T$ was derived and plotted in Fig. $5 f$. Typically, the maximum $S$ value of $0.33 \% \mathrm{~K}^{-1}$ was achieved at
$100 \mathrm{~K}$, which is comparable to that of thermal sensing based on $\mathrm{Er}^{3+}$-activated upconversion nanoprobes [68-70]. The high temperature sensitivity, along with the large absorbance of $\mathrm{Ce}^{3+}$ at $430 \mathrm{~nm}$ and the NIR-II emission of $\mathrm{Er}^{3+}$ in the optical communication window, enables $\mathrm{SrS}: \mathrm{Ce}^{3+} / \mathrm{Er}^{3+} \mathrm{NCs}$ as blue-LEDexcitable NIR-II luminescent nanoprobes for cryogenic temperature sensing in space and energy exploration [71-73].

\section{CONCLUSIONS}

In summary, we have systematically investigated $\mathrm{Ln}^{3+}$-doped $\mathrm{SrS}$ NCs from the controlled synthesis and optical properties to their potential application as a ratiometric temperature sensor. Upon doping with a trace amount $(0.1 \mathrm{~mol} \%)$ of $\mathrm{Ce}^{3+}$, the NCs exhibited bright blue-green PL at 478 and $530 \mathrm{~nm}$ with a PLQY of $6.1 \%$. Through sensitization by the allowed $4 \mathrm{f} \rightarrow 5 \mathrm{~d}$ transition of $\mathrm{Ce}^{3+}$ in the blue region, intense NIR-II luminescence from $\mathrm{Er}^{3+}$ at $1539 \mathrm{~nm}$ and $\mathrm{Nd}^{3+}$ at $1081 \mathrm{~nm}$ with PLQYs of $2.9 \%$ and $2.3 \%$, respectively, was achieved in $\mathrm{Ce}^{3+} / \mathrm{Er}^{3+}$ and $\mathrm{Ce}^{3+} / \mathrm{Nd}^{3+}$ codoped SrS NCs. By means of temperature-dependent steadystate and transient PL spectroscopies, a phonon-assisted ET from $\mathrm{Ce}^{3+}$ to $\mathrm{Er}^{3+}$ was unveiled. Furthermore, owing to the strong CF level splitting exerted by $\mathrm{SrS}$, the $\mathrm{Er}^{3+}$ luminescence was characterized by sharp and well-resolved CF emission peaks, which enables $\mathrm{SrS}: \mathrm{Ce}^{3+} / \mathrm{Er}^{3+} \mathrm{NCs}$ as blue-LED-excitable NIR-II luminescent nanoprobes for non-contact temperature detection based on the thermally coupled Stark sublevels of ${ }^{4} \mathrm{I}_{13 / 2}$ of $\mathrm{Er}^{3+}$. These findings provide fundamental insights into the optical properties and excited-state dynamics of $\mathrm{Ln}^{3+}$ in SrS NCs, thus 

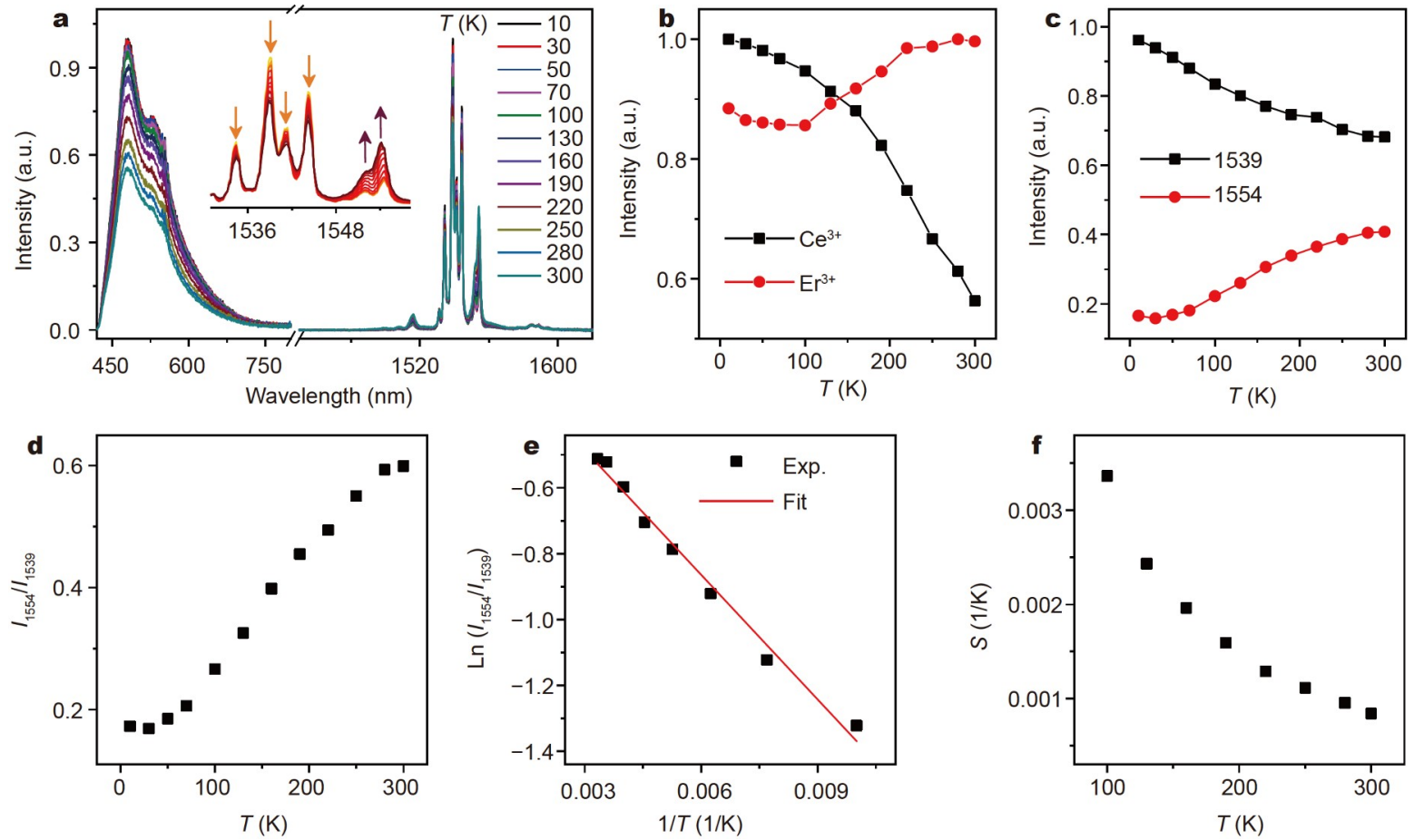

Figure 5 (a) Temperature-dependent PL emission spectra $\left(\lambda_{\text {ex }}=430 \mathrm{~nm}\right)$ of SrS: $0.1 \% \mathrm{Ce}^{3+} / 0.5 \% \mathrm{Er}^{3+} \mathrm{NCs}$. The inset enlarges the ${ }^{4} \mathrm{I}_{13 / 2} \rightarrow{ }^{4} \mathrm{I}_{15 / 2} \mathrm{CF}$ transitions of $\mathrm{Er}^{3+}$, showing drastically different temperature dependence for the CF transition lines of $\mathrm{Er}^{3+}$. Integrated PL intensities for (b) the green emission of Ce ${ }^{3+}$, the NIR-II emission of $\mathrm{Er}^{3+}$, and (c) the ${ }^{4} \mathrm{I}_{13 / 2} \rightarrow{ }^{4} \mathrm{I}_{15 / 2} \mathrm{CF}$ transitions of $\mathrm{Er}^{3+}$ at 1539 and $1554 \mathrm{~nm}$ as a function of temperature. (d) PL intensity ratio between the CF emission peaks of $\mathrm{Er}^{3+}$ at 1554 and $1539 \mathrm{~nm}\left(I_{1554} / I_{1539}\right)$ as a function of temperature. (e) Plot of the FIR of $I_{1554} / I_{1539}$ versus the inverse temperature. (f) The temperature sensitivity $(S)$ of $\mathrm{SrS}: \mathrm{Ce}^{3+} / \mathrm{Er}^{3+}$ nanoprobes as a function of temperature.

laying a foundation for future design of novel NIR-II luminescent nanoprobes based on $\mathrm{Ln}^{3+}$-doped sulphides for applications such as deep-tissue temperature detection.

\section{Received 13 August 2021; accepted 16 September 2021; published online 2 November 2021}

1 Sun Z, Huang H, Zhang R, et al. Activatable rare earth near-infrared-II fluorescence ratiometric nanoprobes. Nano Lett, 2021, 21: 6576-6583

2 Li H, Wang X, Ohulchanskyy TY, et al. Lanthanide-doped near-infrared nanoparticles for biophotonics. Adv Mater, 2021, 33: 2000678

3 Zhong Y, Dai H. A mini-review on rare-earth down-conversion nanoparticles for NIR-II imaging of biological systems. Nano Res, 2020, 13: $1281-1294$

4 Lei P, Feng J, Zhang H. Emerging biomaterials: Taking full advantage of the intrinsic properties of rare earth elements. Nano Today, 2020, 35: 100952

5 Li Z, Ding X, Cong H, et al. Recent advances on inorganic lanthanidedoped NIR-II fluorescence nanoprobes for bioapplication. J Lumin, 2020, 228: 117627

6 Fan Y, Zhang F. A new generation of NIR-II probes: Lanthanide-based nanocrystals for bioimaging and biosensing. Adv Opt Mater, 2019, 7: 1801417

7 Gu Y, Guo Z, Yuan W, et al. High-sensitivity imaging of time-domain near-infrared light transducer. Nat Photonics, 2019, 13: 525-531

$8 \mathrm{Xu}$ J, Gulzar A, Yang P, et al. Recent advances in near-infrared emitting lanthanide-doped nanoconstructs: Mechanism, design and application for bioimaging. Coord Chem Rev, 2019, 381: 104-134

9 Cai Y, Wei Z, Song C, et al. Optical nano-agents in the second nearinfrared window for biomedical applications. Chem Soc Rev, 2019, 48: 22-37

10 Li D, He S, Wu Y, et al. Excretable lanthanide nanoparticle for biomedical imaging and surgical navigation in the second near-infrared window. Adv Sci, 2019, 6: 1902042

11 Skripka A, Morinvil A, Matulionyte M, et al. Advancing neodymium single-band nanothermometry. Nanoscale, 2019, 11: 11322-11330

12 Yu S, Tu D, Lian W, et al. Lanthanide-doped near-infrared II luminescent nanoprobes for bioapplications. Sci China Mater, 2019, 62: 1071-1086

13 Ren F, Liu H, Zhang H, et al. Engineering NIR-IIb fluorescence of Erbased lanthanide nanoparticles for through-skull targeted imaging and imaging-guided surgery of orthotopic glioma. Nano Today, 2020, 34: 100905

14 Bai G, Lyu Y, Wu Z, et al. Lanthanide near-infrared emission and energy transfer in layered $\mathrm{WS}_{2} / \mathrm{MoS}_{2}$ heterostructure. Sci China Mater, 2020, 63: 575-581

15 Gao C, Han Y, Zhang K, et al. Templated-construction of hollow $\mathrm{MoS}_{2}$ architectures with improved photoresponses. Adv Sci, 2020, 7: 2002444

16 Jia $\mathrm{M}, \mathrm{Fu} \mathrm{Z}$, Liu G, et al. NIR-II/III luminescence ratiometric nanothermometry with phonon-tuned sensitivity. Adv Opt Mater, 2020, 8: 1901173

$17 \mathrm{Xu}$ J, Shi R, Chen G, et al. All-in-one theranostic nanomedicine with ultrabright second near-infrared emission for tumor-modulated bioimaging and chemodynamic/photodynamic therapy. ACS Nano, 2020, 14: 9613-9625

18 Yang J, He S, Hu Z, et al. In vivo multifunctional fluorescence imaging using liposome-coated lanthanide nanoparticles in near-infrared-II/IIa/ IIb windows. Nano Today, 2021, 38: 101120

19 Nexha A, Carvajal JJ, Pujol MC, et al. Lanthanide doped luminescence nanothermometers in the biological windows: Strategies and applications. Nanoscale, 2021, 13: 7913-7987

20 Chen R, Zhou X, Wu Y, et al. NIR-II emissive lateral flow immunoassay for accurate determination of tumor marker in hemolysis. Sens Actuat B-Chem, 2021, 328: 129050

21 Wang T, Wang S, Liu Z, et al. A hybrid erbium(III)-bacteriochlorin near-infrared probe for multiplexed biomedical imaging. Nat Mater, 2021, doi: 10.1038/s41563-021-01063-7 
22 Xu M, Zou X, Su Q, et al. Ratiometric nanothermometer in vivo based on triplet sensitized upconversion. Nat Commun, 2018, 9: 2698

23 Han S, Deng R, Gu Q, et al. Lanthanide-doped inorganic nanoparticles turn molecular triplet excitons bright. Nature, 2020, 587: 594-599

24 Ding S, Lu L, Fan Y, et al. Recent progress in NIR-II emitting lanthanide-based nanoparticles and their biological applications. J Rare Earths, 2020, 38: 451-463

25 Ji $\mathrm{Y}, \mathrm{Xu} \mathrm{W}$, Ding $\mathrm{N}$, et al. Huge upconversion luminescence enhancement by a cascade optical field modulation strategy facilitating selective multispectral narrow-band near-infrared photodetection. Light Sci Appl, 2020, 9: 184

26 Lei Z, Zhang F. Molecular engineering of NIR-II fluorophores for improved biomedical detection. Angew Chem Int Ed, 2021, 60: 1629416308

27 Wang $\mathrm{C}$, Lin $\mathrm{H}$, Ge $\mathrm{X}$, et al. Dye-sensitized downconversion nanoprobes with emission beyond $1500 \mathrm{~nm}$ for ratiometric visualization of cancer redox state. Adv Funct Mater, 2021, 31: 2009942

28 Yang Y, Tu D, Zhang Y, et al. Recent advances in design of lanthanidecontaining NIR-II luminescent nanoprobes. iScience, 2021, 24: 102062

29 Huang J, Pu K. Activatable molecular probes for second near-infrared fluorescence, chemiluminescence, and photoacoustic imaging. Angew Chem Int Ed, 2020, 59: 11717-11731

30 Zhang $\mathrm{H}$, Chen $\mathrm{ZH}$, Liu X, et al. A mini-review on recent progress of new sensitizers for luminescence of lanthanide doped nanomaterials. Nano Res, 2020, 13: 1795-1809

31 Bao G, Wen S, Lin G, et al. Learning from lanthanide complexes: The development of dye-lanthanide nanoparticles and their biomedical applications. Coord Chem Rev, 2021, 429: 213642

32 George MR, Critchley PE, Whitehead GFS, et al. Modified pyridine-2,6dicarboxylate acid ligands for sensitization of near-infrared luminescence from lanthanide ions $\left(\mathrm{Ln}^{3+}=\mathrm{Pr}^{3+}, \mathrm{Nd}^{3+}, \mathrm{Gd}^{3+}, \mathrm{Dy}^{3+}, \mathrm{Er}^{3+}\right)$. J Lumin, 2021, 230: 117715

33 Wang Q, Liang T, Wu J, et al. Dye-sensitized rare earth-doped nanoparticles with boosted NIR-IIb emission for dynamic imaging of vascular network-related disorders. ACS Appl Mater Interfaces, 2021, 13: 29303-29312

34 Zheng W, Tu D, Huang P, et al. Time-resolved luminescent biosensing based on inorganic lanthanide-doped nanoprobes. Chem Commun, 2015, 51: 4129-4143

35 Huang $\mathrm{P}$, Zheng W, Gong Z, et al. Rare earth ion- and transition meta ion-doped inorganic luminescent nanocrystals: From fundamentals to biodetection. Mater Today Nano, 2019, 5: 100031

36 Li Y, Zhang P, Ning H, et al. Emitting/sensitizing ions spatially separated lanthanide nanocrystals for visualizing tumors simultaneously through up- and down-conversion near-infrared II luminescence in vivo. Small, 2019, 15: 1905344

37 Li Z, Wu J, Wang Q, et al. A universal strategy to construct lanthanidedoped nanoparticles-based activable NIR-II luminescence probe for bioimaging. iScience, 2020, 23: 100962

38 Gao Y, Li R, Zheng W, et al. Broadband NIR photostimulated luminescence nanoprobes based on $\mathrm{CaS}: \mathrm{Eu}^{2+}, \mathrm{Sm}^{3+}$ nanocrystals. Chem Sci, 2019, 10: 5452-5460

39 Wu Y, Fang Y, Li P, et al. Bandwidth-control orbital-selective delocalization of $4 \mathrm{f}$ electrons in epitaxial Ce films. Nat Commun, 2021, 12: 2520

40 Marin R, Jaque D. Doping lanthanide ions in colloidal semiconductor nanocrystals for brighter photoluminescence. Chem Rev, 2021, 121: $1425-1462$

41 Dang P, Li G, Yun X, et al. Thermally stable and highly efficient redemitting $\mathrm{Eu}^{3+}$-doped $\mathrm{Cs}_{3} \mathrm{GdGe}_{3} \mathrm{O}_{9}$ phosphors for wleds: Non-concentration quenching and negative thermal expansion. Light Sci Appl, 2021, 10: 29

42 You W, Tu D, Zheng W, et al. Large-scale synthesis of uniform lanthanide-doped $\mathrm{NaREF}_{4}$ upconversion/downshifting nanoprobes for bioapplications. Nanoscale, 2018, 10: 11477-11484

43 Liu J, Pan L, Shang C, et al. A highly sensitive and selective nanosensor for near-infrared potassium imaging. Sci Adv, 2020, 6: eaax9757

44 Zhou B, Tang B, Zhang C, et al. Enhancing multiphoton upconversion through interfacial energy transfer in multilayered nanoparticles. Nat
Commun, 2020, 11: 1174

45 Huang J, Li J, Zhang X, et al. Artificial atomic vacancies tailor nearinfrared II excited multiplexing upconversion in core-shell lanthanide nanoparticles. Nano Lett, 2020, 20: 5236-5242

46 Zhang M, Zheng W, Liu Y, et al. A new class of blue-LED-excitable NIR-II luminescent nanoprobes based on lanthanide-doped CaS nanoparticles. Angew Chem Int Ed, 2019, 58: 9556-9560

47 Wang S, Zhang C, Zheng W, et al. A general strategy via charge transfer sensitization to achieve efficient NIR luminescence in lanthanide-doped $\mathrm{NaGdS}_{2}$ nanocrystals. J Mater Chem C, 2021, 9: 5148-5153

48 Jarý V, Havlák L, Bárta J, et al. Optical, structural and paramagnetic properties of Eu-doped ternary sulfides $\mathrm{ALnS}_{2}(\mathrm{~A}=\mathrm{Na}, \mathrm{K}, \mathrm{Rb} ; \mathrm{Ln}=\mathrm{La}$, Gd, Lu, Y). Materials, 2015, 8: 6978-6998

49 Zhang C, Zhang M, Zheng W, et al. A new class of luminescent nanoprobes based on main-group $\mathrm{Sb}^{3+}$ emitters. Nano Res, 2021, doi: 10.1007/s12274-021-3454-4

50 Gouget G, Pellerin M, Al Rahal Al Orabi R, et al. Rare-earth sulfide nanocrystals from wet colloidal synthesis: Tunable compositions, sizedependent light absorption, and sensitized rare-earth luminescence. J Am Chem Soc, 2021, 143: 3300-3305

51 Smet PF, Moreels I, Hens Z, et al. Luminescence in sulfides: A rich history and a bright future. Materials, 2010, 3: 2834-2883

52 Wang J, Zhu Y, Grimes CA, et al. Multicolor lanthanide-doped CaS and SrS near-infrared stimulated luminescent nanoparticles with bright emission: Application in broad-spectrum lighting, information coding, and bio-imaging. Nanoscale, 2019, 11: 12497-12501

53 Jia D, Wang X. Alkali earth sulfide phosphors doped with $\mathrm{Eu}^{2+}$ and $\mathrm{Ce}^{3+}$ for LEDs. Optical Mater, 2007, 30: 375-379

54 Huang $\mathrm{P}$, Zheng $\mathrm{W}, \mathrm{Tu} \mathrm{D}$, et al. Unraveling the electronic structures of neodymium in $\mathrm{LiLuF}_{4}$ nanocrystals for ratiometric temperature sensing. Adv Sci, 2019, 6: 1802282

55 Hazra C, Skripka A, Ribeiro SJL, et al. Erbium single-band nanothermometry in the third biological imaging window: Potential and limitations. Adv Opt Mater, 2020, 8: 2001178

56 Van Haecke JE, Smet PF, De Keyser K, et al. Single crystal CaS:Eu and SrS:Eu luminescent particles obtained by solvothermal synthesis. J Electrochem Soc, 2007, 154: J278-J282

57 Chen D, Yu Y, Huang F, et al. Modifying the size and shape of monodisperse bifunctional alkaline-earth fluoride nanocrystals through lanthanide doping. J Am Chem Soc, 2010, 132: 9976-9978

58 Raubach CW, Gouveia AF, de Santana YVB, et al. Towards controlled synthesis and better understanding of blue shift of the CaS crystals. J Mater Chem C, 2014, 2: 2743-2750

59 Hüttl B, Troppenz U, Velthaus $\mathrm{KO}$, et al. Luminescence properties of SrS:Ce ${ }^{3+}$. J Appl Phys, 1995, 78: 7282-7288

60 Zhao Y, Rabouw FT, van Puffelen T, et al. Lanthanide-doped CaS and SrS luminescent nanocrystals: A single-source precursor approach for doping. J Am Chem Soc, 2014, 136: 16533-16543

61 Miyakawa T, Dexter DL. Phonon sidebands, multiphonon relaxation of excited states, and phonon-assisted energy transfer between ions in solids. Phys Rev B, 1970, 1: 2961-2969

62 Salley GM, Valiente R, Güdel HU. Phonon-assisted cooperative sensitization of $\mathrm{Tb}^{3+}$ in $\mathrm{SrCl}_{2}: \mathrm{Yb}$, Tb. J Phys-Condens Matter, 2002, 14: 5461-5475

63 Ravotti F, Benoit D, Lefebvre P, et al. Time-resolved photoluminescence and optically stimulated luminescence measurements of picosecond-excited SrS:Ce, Sm phosphor. J Appl Phys, 2007, 102: 123102

64 Mei S, Zhou J, Sun HT, et al. Networking state of ytterbium ions probing the origin of luminescence quenching and activation in nanocrystals. Adv Sci, 2021, 8: 2003325

65 Zou Q, Huang P, Zheng W, et al. Cooperative and non-cooperative sensitization upconversion in lanthanide-doped $\mathrm{LiYbF}_{4}$ nanoparticles. Nanoscale, 2017, 9: 6521-6528

66 Shinn MD, Sibley WA, Drexhage MG, et al. Optical transitions of $\mathrm{Er}^{3+}$ ions in fluorozirconate glass. Phys Rev B, 1983, 27: 6635-6648

67 Maurice E, Monnom G, Dussardier B, et al. Erbium-doped silica fibers for intrinsic fiber-optic temperature sensors. Appl Opt, 1995, 34: 80198025 
68 Wei J, Lian W, Zheng W, et al. Sub-10 nm lanthanide-doped SrFCl nanoprobes: Controlled synthesis, optical properties and bioimaging. J Rare Earths, 2019, 37: 691-698

69 Brites CDS, Xie X, Debasu ML, et al. Instantaneous ballistic velocity of suspended brownian nanocrystals measured by upconversion nanothermometry. Nat Nanotech, 2016, 11: 851-856

70 Bastos ARN, Brites CDS, Rojas-Gutierrez PA, et al. Thermal properties of lipid bilayers determined using upconversion nanothermometry. Adv Funct Mater, 2019, 29: 1905474

71 Cui Y, Song R, Yu J, et al. Dual-emitting MOF superset of dye composite for ratiometric temperature sensing. Adv Mater, 2015, 27: 14201425

72 Brites CDS, Balabhadra S, Carlos LD. Lanthanide-based thermometers: At the cutting-edge of luminescence thermometry. Adv Opt Mater, 2019, 7: 1801239

73 Zhao Y, Wang X, Zhang Y, et al. Optical temperature sensing of upconversion luminescent materials: Fundamentals and progress. J Alloys Compd, 2020, 817: 152691

Acknowledgements This work was supported by the Science and Technology Cooperation Fund between Chinese and Australian Governments (2017YFE0132300), the National Natural Science Foundation of China (22135008, 12074379, 21875250 and 12004384), the Natural Science Foundation of Fujian Province (2020I0037 and 2021L3024), the Chinese Academy of Sciences/State Administration of Foreign Experts Affairs (CAS/SAFEA) International Partnership Program for Creative Research Teams, and Fujian Science \& Technology Innovation Laboratory for Optoelectronic Information of China (2021ZR125).

Author contributions Wei J, Zheng W and Chen X conceived the projects, wrote the paper and were primarily responsible for the experiments. Wei J, Liu $\mathrm{Y}$ and Zhang $\mathrm{M}$ carried out the synthesis and characterization of the NCs. Wei J, Huang P, Gong Z and Li R measured the PL spectra and analyzed the data. All authors contributed to the general discussion.

Conflict of interest The authors declare that they have no conflict of interest.

Supplementary information Supplementary data are available in the online version of the paper.

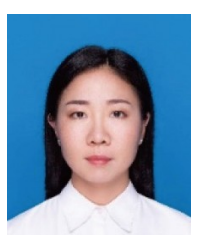

Jiaojiao Wei earned her master's degree from Fujian Normal University (2018). She is currently a PhD student in inorganic chemistry at Fuzhou University. She joined Prof. Xueyuan Chen's group at Fujian Institute of Research on the Structure of Matter (FJIRSM), Chinese Academy of Sciences (CAS) in September 2016. Her research interest focuses on the controlled synthesis and optical spectroscopy of inorganic luminescent nanomaterials.

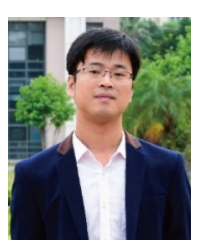

Wei Zheng was born in Fujian province of China. He earned his BSc degree (2007) in material forming and control engineering from Sichuan University and received his $\mathrm{PhD}$ degree (2012) in condensed matter physics from FJIRSM, CAS. He joined Prof. Xueyuan Chen's group in 2012 and was promoted to a professor in 2019. His research interest focuses on the controlled synthesis, optical properties and applications of inorganic luminescent nanomaterials, including lanthanide luminescent nanoparticles and perovskite nanocrystals.

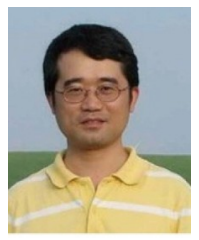

Xueyuan Chen is editor-in-chief of Journal of Luminescence. He earned his BSc degree from the University of Science and Technology of China (1993) and his PhD degree from FJIRSM, CAS (1998). From 2001 to 2005, he was a postdoctoral research associate at the Chemistry Division of Argonne National Laboratory, U.S. Department of Energy, where he studied the photophysics and photochemistry of heavy elements. In 2005, he joined the faculty at FJIRSM, where he is currently a professor and group leader in materials chemistry and physics. His research focuses on the electronic structures, optical properties and applications of inorganic luminescent materials, such as lanthanide (rare-earth) nano-bioprobes and LED phosphors.

\section{蓝光LED可激发的稀土掺杂SrS近红外二区纳米苂光 探针及温度传感}

委娇娇 ${ }^{1,2}$, 刘友宇 ${ }^{1,2}$, 张美然 ${ }^{2}$, 郑伟 $1,2,3^{*}$, 黄萍 $1,2,3$, 宫仲亮 ${ }^{2}$, 李仁 富 ${ }^{2,3}$, 陈学元 $1,2,3^{*}$

摘要 稀土掺杂近红外二区纳米苂光探针在许多技术领域都具有广泛 的应用前景, 但目前受限于稀土离子的 $4 \mathrm{f} \rightarrow 4 \mathrm{f}$ 禁戒跃迁导致材料的吸收 强度弱、发光效率低. 本文报道了一种基于 $\mathrm{SrS}$ 纳米晶 $\mathrm{Ce}^{3+}$ 到 $\mathrm{Er}^{3+}$ 和 $\mathrm{Nd}^{3+}$ 高效能量传递的新型蓝光LED可激发的近红外二区纳米苂光探针. 通过 $\mathrm{Ce}^{3+}$ 的 $4 \mathrm{f} \rightarrow 5 \mathrm{~d}$ 吸收允许跃迁敏化, 该纳米晶可实现 $\mathrm{Er}^{3+}$ 和 $\mathrm{Nd}^{3+}$ 的高 效近红外二区发光, 其苂光量子产率分别为 $2.9 \%$ 和 $2.3 \%$. 利用 $\mathrm{Er}^{3+}$ 的 ${ }^{4} \mathrm{I}_{13 / 2}$ 热耦合晶体场子能级的近红外二区发光, 该纳米晶可作为一种 蓝光LED激发的近红外二区纳米苂光探针用于比率式温度传感. 这些 结果展示了 $\mathrm{SrS}$ : $\mathrm{Ln}^{3+}$ 纳米晶在近红外二区波段的发光优点, 为多功能稀 土硫化物基纳米苂光探针的设计开发提供了新思路. 